\title{
Editorial
}

\section{What makes a good story?}

Place Branding and Public Diplomacy (2010) 6, 263-267. doi:10.1057/pb.2010.33

Countries or regions facing negative media coverage do well to take the trouble to understand, as fully as possible, the strength and nature of those negative perceptions: it is always risky to underestimate their appeal, and the consequent difficulty of combating them.

This is partly based on the old principle of 'know your enemy', and partly because it's hard to tackle public opinion effectively until one fully understands why the public is so firmly attached to its opinions.

Without a proper analysis of the appeal and attraction - both to the media and to its readers and viewers - of negative stories, there is always the risk of insufficient respect for one's enemy, and the rather hubristic approach typical of the shallower public relations agencies, which simply assumes that the media can be persuaded to alter its behaviour and style of reporting by a sufficient number of 'truthful' press releases, abundant use of that magic phrase 'social media', mountains of 'correct' information and the charms of PR executives; it also assumes that public opinion faithfully mirrors the content provided by the media and can be virtually ignored as a separate phenomenon. Both assumptions are demonstrably untrue.

Negative media, when it is very intense, takes on a dimension and a character of its own, and as I have mentioned in a previous Editorial ${ }^{1}$ has more in common with a force of nature, a volcano or an earthquake, than with something of human scale, comprehensible and, which can be tackled, disputed and argued away.
When a country finds itself in the grip of a 'media firestorm' there are a number of reasons why things often have a tendency to get worse, leaving the country's reputation damaged or depleted for years to come, rather than simply burn themselves out in the short term.

Whether the negative situation being covered in the media is a story of crime, corruption, violence, famine or disease, it will always receive most media attention and the country's image is consequently most likely to suffer serious damage when the situation is perceived as dynamic, and worsening. From the point of view of the domestic population in any such situation, this is also an important factor, far more important than the absolute statistics relating to levels of crime, violence, famine or instability: people simply notice that their lives are getting harder. From the point of view of people in other countries, the downward trend means that the story has a compelling plot: human beings are intrinsically more attracted by kinesis than by stasis, and a country suffering from a long-term serious crime problem, for example, is nowhere near as exciting as a country suffering a crime wave and apparently heading for chaos.

Not for nothing are some animals guided by the instinct to 'play dead' in order to avoid predators - something that is not moving simply does not attract attention or engage us as much as something that is.

What happens in the 'real world' must also compete for people's attention against 
the fiction and semi-fiction offered by the entertainment media, and a wave of violent crime, for example, does so effortlessly. In such cases, the ingredients of the 'story' are among the most potent one can find: take the most thrilling, most violent Hollywood gangster movie, and combine it with the most compelling reality TV show, and it is easy to see why a real crime-wave is such a potent media 'product'.

People are always fascinated, sometimes against their better instincts, by the spectacle of a falling man or a failing state. This schadenfreude is why traffic accidents always cause traffic jams: we are unable to take our eyes off the sight of one of our species falling or failing. Part of the reason is doubtless the simple fact that, seen from a position of comfort and safety, the spectacle of others in danger and discomfort increases our sense of comfort, just as we enjoy sitting comfortably indoors and enjoying the spectacle of a thunderstorm outside.

It is clear from the study of public perceptions of countries that public opinion will never voluntarily 'trade down' from an exciting story to a boring story, no matter how true or fair the boring story might be. Governments often fall into the error of believing that good stories will kill bad ones, but they are usually wrong. As a rule, strong stories can only be killed by stronger ones.

It might seem as if finding a more exciting story than, for example, the violent, downwardly spiralling thriller-cum-reality show described above is entirely impossible, but this is not necessarily so. First of all, even though most news stories of crime and disorder are undeniably potent, they are seldom very original, and usually follow a very predictable pattern: indeed, in an imaginary situation where one was actually trying to devise the most powerful story for wrecking the image of a country, one might well reject most of the negative news stories one sees in an average week, simply because they are so unoriginal. And despite the strong appeal - perhaps against many people's better judgment - of stories of human suffering, there is a tendency for people eventually to become sated with such a diet.
It is ultimately an unfulfilling sort of pleasure, and at some point most people will begin to crave more varied and perhaps even more uplifting fare: this is a phenomenon not very different from the well-documented issue of 'compassion fatigue', which traditional charity promotion eventually creates. After being confronted with the spectacle of others' suffering for long enough, a sense of helplessness and ultimately denial will often set in.

Although governments are frequently heard to complain that the media and public opinion prefer a bad news story to a good news story on principle, this is not actually the case: it is simply that the good news stories are seldom as exciting as the bad. The gap that any government attempting to tackle negative media coverage needs to bridge is to resolve the problems in an effective and imaginative way, and at the same time or subsequently to propose positive stories that are equally true, if possible more relevant to the audience, and above all equally or more exciting than the negative ones. This is no plea for 'sunshine journalism', a notion that would quite understandably fill any serious journalist with dismay, but a serious challenge to produce superior content, and indeed a brief that any good creative agency would be delighted to be given.

The recent rescue of the trapped miners in Chile, which dominated the news worldwide for many days, clearly shows that neither media nor public opinion have any intrinsic objection to positive stories - indeed, they can clearly take enormous interest and pleasure in them but there are a few essential components in order for such episodes to gain this level of attention. First of all, they need to be kinetic rather than static: it must be a 'developing story' with a strong narrative, and preferably involving suspense, drama and danger.

Secondly, they need to have human interest a story without personalities or human relationships is only half a story. Thirdly, the narrative needs to be relatively clear and 'clean' - in the case of the Chilean mine rescue, it could hardly have been simpler: success was the safe 
evacuation of each miner from the ground; failure was the death of any of the miners or the failure of the rescue plan. Each miner who appeared at the surface represented exactly one thirty-third of total success, and the television audience could see the tally mount up towards a perfect resolution of the problem. A more complex situation, such as the oil spill in the Gulf of Mexico, to cite another recent example, provides a far less satisfying spectacle, because neither complete success nor complete failure are possible or easy to measure, understand or recognise.

Of course, one cannot very easily go about engineering such a situation either in order to gain profile for a country, or to combat negative media, but such rules of thumb - and it could be a useful exercise to develop such rules in a more exhaustive and rigorous way against a number of comparable events - might help in judging whether an existing situation or narrative has the potential to gain traction in the media.

Another factor that should be taken into consideration when analysing situations in which a country is suffering from persistent negative media is the extent of the country's vulnerability to the negative reporting in the first place. Countries with very good, very broad and complex reputations frequently show a remarkable immunity to negative events: this is often a fairly straightforward matter of the degree of knowledge people have about the country in the first place, and the consequent proportion of negative elements to the overall image.

Perhaps the most striking example of this issue of immunity or vulnerability can be found in the case of the infamous cartoons lampooning the Prophet Mohammad. Before 2006, Denmark's image in Egypt as recorded in the Anholt Nation Brands Index was positive but very simple: truly a 'brand', indeed, in the sense that the country was represented in the minds of most Egyptians by a rather simplified stereotype, based on relatively little knowledge of the country. It was perceived as a Scandinavian country, and consequently was admired for its presumed attributes of stability, order, prosperity, transparency, equality and so forth. Following the cartoons episode, Denmark sank virtually to the bottom of the Egyptian panel's list of admired countries in the Anholt Nation Brands Index. The United States, however, never dropped more than a handful of places in the $\mathrm{NBI}$, despite its invasion and military occupation of two predominanly Muslim countries: by any measure a more controversial way of behaving. One plausible explanation for this notable disparity in response is simply the fact that the United States was far beyond a 'brand' in the minds of the populations polled in the study: it was known for such a wide array of different qualities and characteristics, some positive and some negative, that even the addition of egregious behaviour could never amount to a very large proportion of people's overall perceptions of the country. The perception that Denmark had insulted Islam formed one-half of the country's image, with consequent catastrophic - and as yet unreversed consequences for that image.

A country can enjoy a good and positive general reputation, but if, for example, acceptance and social inclusion, or at least some related qualities, are not a specific and noted part of that reputation, then the country's image is likely to prove more vulnerable than otherwise to events, which appear to suggest that its society is intolerant or racist. Indian perceptions of Australia before a series of attacks on Indian students in Melbourne became headline news had been extremely positive - and these positive perceptions were indeed borne out by the large numbers of Indian students choosing to study in Australia but social equality and inclusiveness did not form a particularly significant part of Australia's image in India. It was certainly not regarded as an intolerant or unfair society, but compared with those countries that tend to feature such qualities as a well-established core component of their reputations (such as Sweden, the Netherlands, Singapore and Canada, for example), Australia enjoyed no particular reputation.

In 2008, the Indian panel in the Anholt-GfK Roper Nation Brands Index ranked Australia seventh on the question relating to perceptions 
of 'equality in society'. By the 2010 study, this ranking had dropped to 34 th, a very striking alteration in a survey which tends to be characterised by its stability. It is an interesting question whether such a drop would have been recorded had similar events taken place in one of the countries particularly perceived by Indians as tolerant and inclusive, and this author's hypothesis is that it would not.

Prior perceptions can have a powerful determining effect on people's experience of countries or their people, and their consequent perceptions after that experience. The evidence is somewhat anecdotal and would need further investigation, but this author has often noted that people with a strong bias in favour of a particular country will often tend to blame themselves if they visit that country and have a negative experience, whereas they will blame the country if they have a negative experience in a country about which they had no very clear positive prejudice before visiting. The suggestion is that perceptions of a country have greater and more far-reaching effects than often supposed, and do not simply cease to have an effect once they have stimulated the decision to visit, to invest, or to purchase that country's products: they may indeed have an impact on the way in which that 'purchasing experience' is interpreted in the mind of the 'purchaser' and on his or her subsequent perceptions after the event.

Certainly, these issues tend to support the idea of building a nation's standing as an 'insurance policy' against events that might threaten its international standing in the future. Clearly one can not predict what might go wrong in the future, nor can one store up reputation against it unless one also happens to deserve that reputation, but some imaginative scenario planning can surely only be a beneficial exercise in the light of these effects. A country can take a careful look at where it does deserve a better reputation and build that up, and it can also take a careful look at things that might go wrong in the future and ensure that it builds up both the capability and the reputation that goes with it to combat those things well in advance.
Ultimately however, whether it is before or after the event, the need is to find ways to encourage people to change their minds about a country; to adduce evidence that compels a reappraisal of the type of place it is. The reason why the kinds of headline-grabbing events described earlier are of such interest, as distinct from ordinary, deliberate, promotional or communications activities, is clearly because they have the power to arrest attention before they deliver the evidence. This is crucial: for any country attempting to bring about a change in international perceptions in a big and crowded world, simply attracting the attention of the media and of public opinion in the first place is as significant a challenge as proving to them that a change of mind is called for.

However, this author has observed that attracting attention and producing compelling evidence to justify a change of mind are necessary but not sufficient conditions: a third factor seems equally important, and this is what might be termed the 'interpretative key'. The interpretative key is an additional event, set of events or knowledge that ascribes the power to the new evidence to change a pre-existing belief - in other words, it is the factor that reassures the observer that the change in behaviour is not merely anomalous.

For example, the United States was regarded in 2008 by a significant proportion of the 20000 respondents in the Anholt-GfK Roper Nation Brands Index as a selfish and aggressive country that displayed little interest in the suffering of people in other countries (the prior perception). The US government continued to make enormous efforts in poverty reduction and emergency aid, outspending the vast majority of other wealthy countries in these activities (the compelling evidence), which was often widely reported in the case of wellcovered humanitarian disasters such as the Pakistan earthquake in 2006 (which attracted the attention of international public opinion to the compelling evidence); yet the perception remained largely unaltered. Once President Obama was elected, however, despite the fact that US international assistance policy 
continued more or less on its usual course, the Nation Brands Index recorded steady rises in international perceptions of the country's commitment to reducing poverty in other countries: in other words, the change of regime, and the consequent perceived change of tone in US foreign policy, had provided the interpretative key which allowed people to regard the aid donations as not anomalous, but as valid justifications for an altered perception.

National standing continues to be a concern for government, business and society in general, and its impact on the 'life of the nation' is undoubted. A prudent and foresighted attitude to reputational risk is surely one of the defining characteristics of good and responsible governance in this age where perception so often seems to trump reality.

\section{NOTE}

1 PBPD 5.3 The Media and National Image.

Simon Anholt Managing Editor 